\title{
An Integrative Framework of Cooperative Advertising: Should Manufacturers Continuously Support Retailer Advertising?
}

\author{
Guiomar Martín-Herrán ${ }^{1, *}$, Simon P. Siguée,**
}

\begin{abstract}
A two-period game is developed in a bilateral monopoly where, besides pricing decisions, the retailer and manufacturer can set their advertising and cooperative advertising support rates for each period. It is demonstrated that, in addition to the established continuous cooperative advertising programs, in which the retailer advertises and the manufacturer supports retailer advertising in each period, two other advertising schedules are possible. First, the retailer advertises in each period, while the manufacturer only supports the second-period advertising. Second, whether or not the manufacturer provides a cooperative advertising program in the first period, the retailer only advertises in the second period and receives advertising support. The conditions under which each of these advertising arrangements is implemented are identified. In a continuous cooperative advertising schedule, the manufacturer may change his advertising support over time depending on the nature of the long-term effects of retailer advertising. The implications of these findings are discussed. Keywords: Cooperative advertising. Game theory. Pricing. Retailer advertising.
\end{abstract}

\footnotetext{
We thank two anonymous reviewers for their helpful comments and Janice Thiessen for copy-editing assistance. The first author's research is partially supported by MEC under projects ECO2011-24352 and ECO2014-52343-P, co-financed by FEDER funds and the COST Action IS1104 "The EU in the new economic complex geography: models, tools and policy evaluation".

*Departamento de Economía Aplicada (Matemáticas), Universidad de Valladolid, Avda. Valle de Esgueva, 6, 47011, Valladolid, Spain. Tel.: +34 983423330 Fax: +34 983 423299; E-mail: guiomar@eco.uva.es

** Corresponding author: Faculty of Business, Athabasca University, 201-13220 St. Albert Trail, Edmonton, AB, T5L 4W1, Canada. Tel.: 780460 0340, E-mail: simons@athabascau.ca

${ }^{1}$ IMUVA, Universidad de Valladolid

${ }^{2}$ Faculty of Business, Athabasca University (Canada)
} 


\section{Introduction}

The optimal design of cooperative advertising programs over time remains a major challenge for both scholars and decision makers. Cooperative advertising is a joint promotional arrangement, whereby a manufacturer reimburses a percentage of advertising expenditures that retailers support in promoting his product. A cooperative advertising program aims at providing additional incentives to retailers to increase their local advertising of a manufacturer's product. Retailer advertising is believed to benefit manufacturers in three ways. First, retailers have a better knowledge of their local markets and can therefore undertake more effective advertising programs for manufacturers' products. Second, retailers use local media, which generally apply lower advertising rates than do national media. Finally, retailer local advertising is known to stimulate immediate sales at the retail level, although its longterm effects on sales remain controversial (Jørgensen et al., 2000, 2001, 2003; Herrington and Dempsey, 2005).

Two research streams have investigated the optimal design of cooperative advertising programs to retailers (See Aust and Buscher (2014) and Jørgensen and Zaccour (2014) for review). The first research stream uses static games. The optimal strategies derived from these static games apply to a single period and overlook, among others, the now well-established longterm effects of retailer advertising (e.g., Berger, 1972; Huang and Li, 2001; Karray, 2013, 2015; Karray and Amin, 2015; Karray and Zaccour, 2006; Li et al., 2002; Szmerekovsky and Zhang, 2009; Xie and Ai, 2006; Yan, 2010; Yan and Pei, 2015; Yan et. al., 2016). The findings of this research stream are known to be more relevant in circumstances where the decision environment is relatively stable and channel members' decisions do not have carryover effects (Jørgensen and Zaccour, 2014). As a consequence, it is implicitly believed that channel members' decisions related to cooperative advertising do not change over time.

The second research stream uses sophisticated dynamic models and seeks to study more realistic cooperative advertising situations where the environment can change and channel decisions can have long-term effects. Most works in this second research stream uses differential games (e.g., Jørgensen et al., 2000, 2001, 2003; He et al. 2011; Sigué and Chintagunta, 2009; Zhang et al., 2013, 2015). For mathematical tractability, however, these works have studied infinite horizon cooperative advertising contracts and mainly derived stationary feedback strategies, as they all use time-independent parameters. Not surprising, these works mainly prescribe constant cooperative advertising support rates that do not change over time.

In their recent review of cooperative advertising works, Jørgensen and Zaccour (2014) pointed out the exclusive prescription of stationary cooperative advertising rates as a serious 
shortcoming of the current literature. In the real world, cooperative advertising programs, as many other promotional activities, are offered within limited time periods and their support rates are barely constant over time. Among other strategies, manufacturers change their cooperative advertising contributions depending on seasonal periods and the type of local advertising they want to stimulate. A manufacturer may choose to support retailer advertising exclusively when the sales in the industry are at the seasonal peak. Similar practices are known in the advertising literature as pulsing, when advertisers alternate between zero and positive advertising levels (Sasieni, 1989; Villas-Boas, 1993). For example, Mitsubishi Motors (2012) developed a three-month cooperative advertising program in 2012 that went from April 3 to July 2. Honda Canada Inc. (2010) has a flexible annual cooperative advertising policy, which allows special rates to support specific dealers' sales initiatives. On the other hand, while cooperative advertising programs set very specific requirements for the use of funds, they are generally flexible and give enough freedom to retailers to use or not to use them during a given period. As a matter of fact, while all authorized Mitsubishi Motors North America dealers were eligible to participate in the 2012 cooperative advertising program, only those who endeavored to meet the program requirements were able to take advantage of it.

There is therefore a need to further explore what drives the changes in both cooperative advertising programs and retailer advertising schedules over time. This paper hopes to contribute an integrative framework that can explain observed practices in the business world and provide useful guidelines to help implement more effective cooperative advertising programs. On the theoretical ground, this paper helps to integrate some of the findings of previous static and dynamic cooperative advertising models in bilateral monopoly contexts. Following these works, we develop a stylized two-period model in which a manufacturer sells a single brand to a retailer. In each period, the manufacturer determines the optimal wholesale price and cooperative advertising support rate, while the retailer sets the optimal rate of local advertising and retail price. This setup allows various cooperative advertising and retailer advertising schedules to be considered as potential equilibria. Technically, unlike current differential games-based models that prescribe a constant cooperative advertising rate over time, in our proposed configuration, the manufacturer may or may not offer cooperative advertising support from one period to another. In response, the retailer may or may not advertise in a given period even if cooperative advertising support is provided. The research questions then are:

1. Should the retailer continuously advertise? And should the manufacturer continuously support retailer advertising? 
2. What are the drivers of change in the players' strategies over time?

3. What types of cooperative advertising arrangements should the manufacturer and retailer implement over time if they both act so as to maximize their individual profits?

To address these questions, we use the Stackelberg solution concept to derive equilibria in a game where the manufacturer is assigned the leadership role. This research differs from previous works in several ways. First, we disregard competition, which is studied in several recent works and proven to affect cooperative advertising decisions, to focus on vertical interactions over time (Karray, 2015; Karray and Amin, 2015; Yan and Pei, 2015; Yan et al., 2016).

Second, we consider unconstrained cooperative advertising programs for which the manufacturer does not set a maximum contribution to his cooperative advertising program as a percentage of the retailer's purchases. The 2012 Mitsubishi Motors cooperative advertising program referred to above is a good example of a constrained cooperative advertising program. It has been recently demonstrated that, even in a bilateral monopoly context, when such a constraint is used, an increase of the manufacturer's cooperative advertising support may not translate to an increase of retailer advertising as is otherwise expected (Zhang et al., 2015). In this particular case, our work is more in line with the majority of previous cooperative advertising works.

Third, unlike previous static cooperative advertising models, this paper acknowledges the possibility of retailer advertising carryover, which means that the first-period retailer advertising may also impact on the second-period demand. Therefore, unless the long-term effects of retailer advertising are set to zero, the game played in the second period cannot be considered as a mere successive static game.

Finally, compared to infinite horizon cooperative advertising contracts previously studied in the literature, which exclusively lead to constant cooperative advertising rates, this paper shows that cooperative advertising rates can change over time to support various types of retailer advertising. As a matter of fact, we do not make any restrictive assumption on the role of retailer advertising and its effects, as in some of the published works. Instead, we study the general scenario where, depending on the content of this type of advertising, retailer advertising can have no, negative, and positive carryover effects. Previous works do not simultaneously investigate these three possible effects (He et al., 2014; Jørgensen et al., 2000, 2001, 2003; Sigué and Chintagunta, 2009). In this paper we show that these effects play a critical role in how channel members schedule their advertising decisions.

The remainder of the paper is organized as follows. Section 2 describes the model and 
discusses its assumptions. Section 3 describes the methodology and derives the game equilibrium solutions. Section 4 studies how the manufacturer's and retailer's decisions change over time. Section 5 compares the findings derived in Section 3. Finally, Section 6 concludes and discusses the managerial and theoretical implications of our findings.

\section{The model}

Consider a bilateral monopoly in which a manufacturer enters into an exclusive distribution arrangement with a retailer who then sells the manufacturer's product to consumers. The manufacturer's product faces no direct competition or, when competition does exist as in the automobile industry, it is disregarded to focus on how vertical interactions between channel members affect advertising decisions. Also, because of the exclusive distribution arrangement, there is no intrabrand competition at the retail level. As a matter of fact, the existence of such vertical interactions in advertising has lately led companies such as Toyota and Honda to prohibit certain types of retailer advertising that are believed to damage their brand image (Cole, 2015). Let $a_{i}$ and $s_{i}$ be, respectively, the rate of retailer's local advertising and the manufacturer's cooperative advertising rate or the percentage of the retailer's advertising expenditures that the manufacturer is committed to share in period $i, i \in\{1,2\}$. Also, let $w_{i}$ and $p_{i}$ denote the wholesale and retail prices in period $i, i \in\{1,2\}$. We consider that the retail price is the effective price consumers pay for the product in period $i$.

As in many other papers in the distribution channel literature (Chu and Desai, 1995; Martín-Herrán et al., 2010; Sigué, 2008), we assume the following linear demand functions: $q_{1}=g-p_{1}+\alpha a_{1}$ and $q_{2}=g-p_{2}+\beta a_{1}+\alpha a_{2}$. These demand functions are mainly used for convenience and tractability. They can also approximate quite well more complicated functions for both non-durable and durable products (Lilien et al. 1992). The parameter $g$ is positive and represents the baseline demand at the start of the game. For simplicity, consumer sensitivity to retail prices in the two periods is normalized to 1 . The parameters $\alpha$ and $\beta$ respectively represent the short-term and long-term effects of retailer advertising. The short-term effects of retailer advertising $(\alpha)$ in the two periods are identical and positive. On the other hand, the long-term effects of the first-period retailer advertising $(\beta)$ on the second-

period demand can be either zero, negative, or positive depending on the type of retailer advertising and the target market. For instance, $\beta$ can take negative values when retailer advertising hurts the brand image or goodwill (Jørgensen et al., 2003). Conversely, $\beta$ can takes positive values when the first-period retailer advertising contributes to enhancing the brand image or goodwill (Jørgensen et al., 2000). $\beta$ is set to zero when retailer advertising 
does not have any impact on the second-period demand. This type of retailer advertising is known as promotional advertising, as it exclusively stimulates short-term sales (Jørgensen et al. 2000). Consistent with the empirical findings of the work by Herrington and Dempsey (2005) in the automobile industry, we do not make any a priori assumption on the relative importance of the short-term and long-term effects of retailer advertising. Either effect could be higher than the other depending on the nature of retailer advertising. The baseline demand of the second period is given by: $g+\beta a_{1}$ and depends on the retailer's first-period advertising.

Table 1: Model specification

\begin{tabular}{|l|c|c|}
\hline & Period 1 & Period 2 \\
\hline Manufacturer's controls & $w_{1}, s_{1}$ & $w_{2}, s_{2}$ \\
Retailer's controls & $p_{1}, a_{1}$ & $p_{2}, a_{2}$ \\
Demand functions & $q_{1}=g-p_{1}+\alpha a_{1}$ & $q_{2}=g-p_{2}+\beta a_{1}+\alpha a_{2}$ \\
Manufacturer's profits & $M_{1}=w_{1} q_{1}-\frac{1}{2} s_{1} a_{1}^{2}$ & $M_{2}=w_{2} q_{2}-\frac{1}{2} s_{2} a_{2}^{2}$ \\
Retailer's profits & $R_{1}=\left(p_{1}-w_{1}\right) q_{1}-\frac{1}{2}\left(1-s_{1}\right) a_{1}^{2}$ & $R_{2}=\left(p_{2}-w_{2}\right) q_{2}-\frac{1}{2}\left(1-s_{2}\right) a_{2}^{2}$ \\
\hline
\end{tabular}

The current model specification (see Table 1) assumes that the manufacturer does not undertake any national advertising and fully relies on the retailer's advertising. This assumption is somehow simplistic as, in many cases, manufacturers do not relinquish all advertising responsibilities to retailers (Sigué and Chintagunta, 2009). However, it allows us to focus on retailer advertising and its short-term and long-term effects on the design of cooperative advertising programs over time, which are the focal points of this study.

We assume the following convex costs for retailer advertising, $\frac{1}{2} a_{i}^{2}$. Convex costs are generally used in the literature when advertising decision variables enter linearly in the demand functions (e.g., Chintagunta and Jain, 1992; Jørgensen et al., 2001; Martín-Herrán and Sigué, 2011). They mean that the marginal costs of advertising are increasing. Given the manufacturer's cooperative advertising arrangements, the manufacturer's portions of retailer advertising costs are, $\frac{1}{2} s_{i} a_{i}^{2}$, while the retailer's effective advertising costs are $\frac{1}{2}\left(1-s_{i}\right) a_{i}^{2}$.

Without loss of generality, we assume the production and other administrative costs to be zero. The retailer's $\left(R_{i}\right)$ and manufacturer's $\left(M_{i}\right)$ profits in period $i, i \in\{1,2\}$, are given by:

$$
\begin{aligned}
& R_{1}=\left(p_{1}-w_{1}\right) q_{1}-\frac{1}{2}\left(1-s_{1}\right) a_{1}^{2}, \quad R_{2}=\left(p_{2}-w_{2}\right) q_{2}-\frac{1}{2}\left(1-s_{2}\right) a_{2}^{2}, \\
& M_{1}=w_{1} q_{1}-\frac{1}{2} s_{1} a_{1}^{2}, \quad M_{2}=w_{2} q_{2}-\frac{1}{2} s_{2} a_{2}^{2} .
\end{aligned}
$$


The manufacturer and retailer aim to maximize their respective profits over the two periods: $M=M_{1}+t_{M} M_{2}$ and $R=R_{1}+t_{R} R_{2}$, where $t_{M}$ and $t_{R}$ are the manufacturer's and retailer's discount factors. The discount factors of the two players are normalized to $1\left(t_{M}=\right.$ $\left.t_{R}=1\right)$. The use of a common discount rate for channel members is standard in the literature (e.g., Jørgensen et al., 2001, 2003; Jørgensen and Zaccour, 2014) and captures the idea that, in a bilateral monopoly in which a retailer only sells a manufacturer's product, the two channel members have the same interest in future profits. It is also reasonable to assume that, in the current context of very low interest rates, channel members do not heavily discount future profits.

\section{Equilibria}

The Stackelberg equilibrium concept is used to derive the model equilibria. The manufacturer and retailer are, respectively, the Stackelberg leader and follower. The allocation of roles is done on an ad hoc basis, but the manufacturer's leadership is known to benefit all channel members (Jørgensen et al. 2001). The sequence of moves of the two players is as follows.

Table 2: Sequence of moves

\begin{tabular}{|c|c|c|}
\hline & Player & Decision variables \\
\hline Stage 1 & Manufacturer & $w_{1}, s_{1}$ \\
\hline Stage 2 & Retailer & $p_{1}, a_{1}$ \\
\hline Stage 3 & Manufacturer & $w_{2}, s_{2}$ \\
\hline Stage 4 & Retailer & $p_{2}, a_{2}$ \\
\hline
\end{tabular}

The manufacturer announces his first-period decisions in Stage 1. The retailer reacts to the manufacturer's announcement in Stage 2 to determine her optimal first-period strategies. Subsequently, the manufacturer announces his second-period decisions in Stage 3, which is followed by the reaction of the retailer in Stage 4 as she determines her optimal second-period retail price and advertising rate. In such a configuration, subgame-perfect equilibria are obtained by deriving optimal solutions backwards. Essentially, the retailer's optimal secondperiod strategies $\left(p_{2}, a_{2}\right)$ in Stage 4 are first obtained. Second, the manufacturer's optimal second-period decisions $\left(w_{2}, s_{2}\right)$ in Stage 3 are derived after the introduction of the retailer's optimal second-period decision into the manufacturer's problem. Third, the optimal strategies of Stages 3 and 4 are incorporated into the retailer's first-period problem in Stage 2 to derive 
the retailer's optimal strategies of the period $\left(p_{1}, a_{1}\right)$. Lastly, the manufacturer's first-period decisions $\left(w_{1}, s_{1}\right)$ are obtained knowing the strategies of the previous stages.

We show in Appendix A that the conditions ensuring the strict concavity of the retailer's and manufacturer's profit functions with respect to their second-period decision variables are satisfied. However, the manufacturer's and retailer's profit functions with respect to their firstperiod decision variables could be concave or not. As a result, an interior equilibrium that maximizes the channel members' objective functions may or may not be attained, depending on the values of some model parameters. Further, we characterize the corner solutions and list the conditions that ensure that the problem admits an interior solution (Scenario I). The corner solutions correspond to $s_{1}=0$, a situation where the manufacturer does not provide any cooperative advertising support to the retailer in the first period (Scenario II), and $a_{1}=0$, a situation where the retailer does not undertake any advertising (Scenario III). Our analysis focuses on these two corner solutions together with the interior solution, which are relevant to the planning of cooperative advertising programs over time as addressed in this paper. The following proposition characterizes these three possible Stackelberg equilibrium solutions.

Proposition 1. There exist three Stackelberg equilibria that correspond to the following three scenarios:

1. Scenario I: Under conditions (B.1)-(B.10) in Appendix B, the retailer advertises and the manufacturer offers an advertising support to the retailer in each period.

2. Scenario II: Under conditions (C.1)-(C.3) in Appendix C, the retailer advertises in each period, but the manufacturer only supports the retailer's second-period advertising.

3. Scenario III: Regardless of whether or not the manufacturer offers a cooperative advertising program in the first period, the retailer only advertises in the second period and receives advertising support from the manufacturer.

Proof. See Appendices A, B and C.

The strategies in Appendix A show that, in Scenarios I and II, except for the second-period cooperative advertising support rate, all other decision variables depend on the parameters $\alpha$ and $\beta, \alpha \in(0,1)$ and $\beta \in(-1,1)$. Therefore, some conditions have to be imposed on these parameters to ensure positive strategies. These conditions are displayed in Figure 1 below.

Scenario I (Figure 1) is not feasible when retailer advertising produces relatively large negative carryover effects, regardless of its short-term effects. Because retailer advertising that produces large negative carryover effects significantly reduces the second-period baseline demand, it is neither in the interest of the retailer to continuously undertake this type of advertising nor in the interest of the manufacturer to support it (Jørgensen et al., 2003). 
Also, the case where both the short-term and long-term effects of retailer advertising simultaneously take very large values (top right of Figure 1) is not feasible as well. Due to very large advertising effects, advertising expenditures can reach levels that are not economically sustainable to channel members. Between these two extremes, the retailer can continuously invest in advertising in the two periods and the manufacturer can find it optimal to support retailer advertising providing that it does not dramatically hurts long-term sales. As a matter of fact, small damages to the brand image can be compensated by short-term incentives that boost current sales. It is therefore not surprising to see that major automakers have cooperative advertising policies in place that prevent them from supporting promotional activities that can substantially harm their brand. For instance, Honda Canada Inc. prohibits retailer advertising that implies a distressed sales environment, and requires retailer advertising to have a minimum of two benefit descriptions for the featured products, and to properly use its logo.

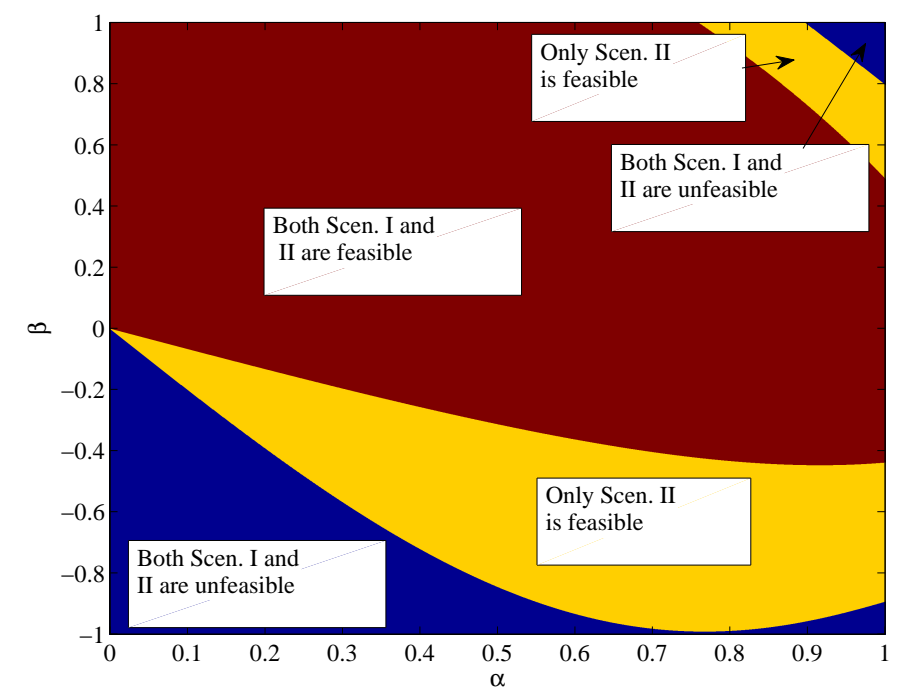

Figure 1: Feasible and unfeasible regions for scenarios I and II. 
Scenario II (Figure 1) is not feasible mainly when retailer advertising combines small short-term effects with negative carryover effects. Current advertising-induced sales are not enough to counterbalance the decrease of the second-period baseline demand. As above, extreme cases of large short-term and positive long-term effects are also unfeasible because of cost implications. Observe however that retailer advertising that highly impacts shortterm sales can be undertaken even if it has large negative carryover effects. This is because the manufacturer's advertising support to the second-period retailer advertising contributes to increasing retailer advertising and consequently helps to mitigate the negative carryover effects of the first-period advertising. The second-period cooperative advertising program will become less attractive if the model is expanded to three periods and the second-period advertising negatively affects the third-period sales.

In Scenario III, the two players' strategies are all positive regardless of the parameter values, which means that players can play this equilibrium with any type of retailer advertising. Particularly, the first-period retailer's and manufacturer's prices are positive as expected in a simple pricing game. The second-period retailer's and manufacturer's prices as well as the second-period retailer's advertising all depend exclusively on the short-term effects of retailer advertising. The retailer's decision not to advertise in the first period renders irrelevant the carryover effects of advertising in this scenario.

Summarizing, the manufacturer offers a cooperative advertising program in the first and second periods only under some specific conditions related to the effects of retailer advertising. Any corner solution equilibrium chosen does not lead to an effective cooperative advertising program in the first period. This is because either the manufacturer endogenously finds it not optimal to support the retailer's advertising in the first period mainly due to its negative carryover effects (Scenario II) or the retailer does not undertake advertising to reduce her advertising expenses over the two periods (as in Scenario III). The fact that the retailer does not undertake local advertising nullifies any cooperative advertising program that the manufacturer may consider implementing. Hereafter, we will therefore assume that $s_{1}^{I I I}=0$.

\section{Players' strategies over time}

We now investigate whether or not the manufacturer's and retailer's decisions change from the first to the second period. The findings of the comparisons of the players' strategies for the two periods under each of the three scenarios are summarized in Proposition 2.

Proposition 2. The players' decisions in the first and second periods compare as follows:

1. In Scenario I: For any $\alpha \in(0,1)$, 
(a) If $\beta=0$, then $s_{1}^{I}=s_{2}^{I}=1 / 3, \quad a_{1}^{I}=a_{2}^{I}, \quad w_{1}^{I}=w_{2}^{I}, \quad p_{1}^{I}=p_{2}^{I}$.

(b) If $\beta \in(0,1)$, then $s_{1}^{I}>s_{2}^{I}=1 / 3, a_{1}^{I}>a_{2}^{I}, w_{1}^{I}<w_{2}^{I}, p_{1}^{I}<p_{2}^{I}$.

(c) If $\beta \in(-1,0)$, then $s_{1}^{I}<s_{2}^{I}=1 / 3, \quad a_{1}^{I}<a_{2}^{I}$, and $w_{1}^{I}$ and $p_{1}^{I}$ can be greater or lower than $w_{2}^{I}$ and $p_{2}^{I}$, respectively.

2. In Scenario II: For any $\alpha \in(0,1)$,

(a) If $\beta=0$, then $w_{1}^{I I}<w_{2}^{I I}, p_{1}^{I I}<p_{2}^{I I}, \quad a_{1}^{I I}<a_{2}^{I I}$.

(b) If $\beta \in(0,1)$, then $w_{1}^{I I}<w_{2}^{I I}, p_{1}^{I I}<p_{2}^{I I}$ and $a_{1}^{I I}$ can be greater or lower than $a_{2}^{I I}$.

(c) If $\beta \in(-1,0)$, then $p_{1}^{I I}<p_{2}^{I I}$ and $w_{1}^{I I}$ and $a_{1}^{I I}$ can be greater or lower than $w_{2}^{I I}$ and $a_{2}^{I I}$, respectively.

(d) $s_{1}^{I I}=0<s_{2}^{I I}=1 / 3$.

3. In Scenario III: For any $\alpha \in(0,1), \beta \in(-1,1)$, the following inequalities apply:

$$
a_{1}^{I I I}=0<a_{2}^{I I I}, \quad s_{1}^{I I I}=0<s_{2}^{I I I}=1 / 3, \quad p_{1}^{I I I}<p_{2}^{I I I}, \quad w_{1}^{I I I}<w_{2}^{I I I} .
$$

Proof. The results of the comparison for the first and second scenarios can be easily derived using Mathematica 10.0.

The findings of Scenario I critically depend on the short-term and long-term effects of retailer advertising as illustrated in Figure 2 (In this figure and hereafter, UF denotes the unfeasible region of the corresponding scenario). In this scenario, when the first-period retailer advertising does not carry over to the second period, all the players' decisions of the two periods are identical. This result is intuitive. Consumer demands in the two periods are independent when $\beta=0$. The two-period game in this particular case can be considered as two successive static games in a stable environment. Players' strategies remain, therefore, unchanged over time. Such strategies are comparable to steady-state strategies in differential games-based models (e.g., Jørgensen et al., 2000; Sigué and Chintagunta, 2009).

On the other hand, unlike steady-state strategies, when retailer advertising positively impacts on the second-period demand $(\beta>0)$, the retailer invests more in advertising and the manufacturer supports a bigger share of retailer advertising in the first period to expand the second-period baseline demand.The expanded second-period demand allows both the manufacturer and retailer to respectively increase their second-period wholesale and retail prices. When retailer advertising harms long-term sales $(\beta<0)$, as expected, the retailer invests less in advertising and the manufacturer provides a smaller cooperative advertising support rate in the first period to limit adverse effects of retailer advertising. Less intuitive, however, is the finding that the two players may charge higher or lower wholesale and retail prices in either period of the game depending on the magnitude of both the short-term and negative long-term 


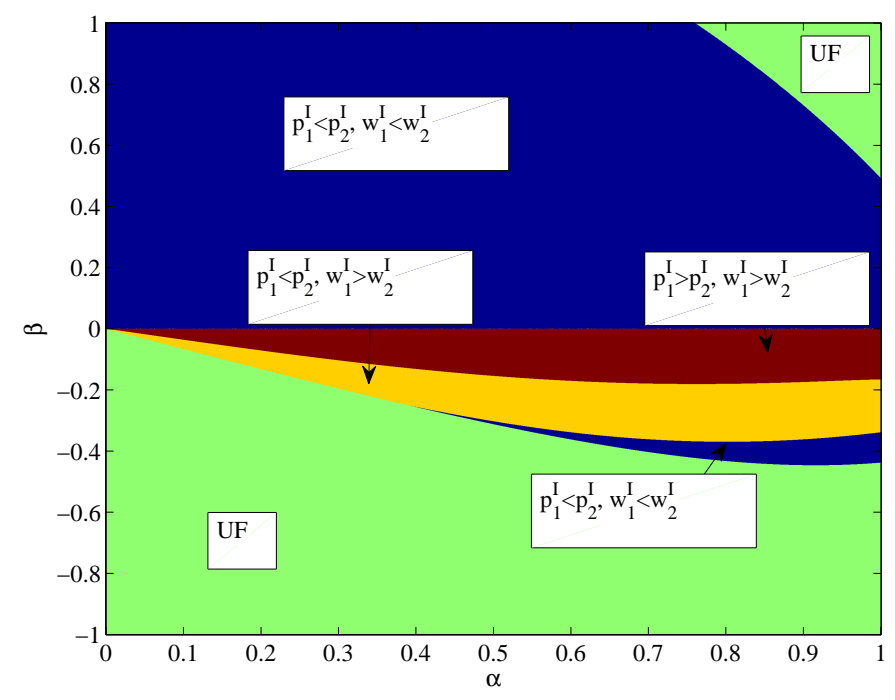

Figure 2: Scenario I: Comparison retail and wholesale prices for the first and second periods.

effects of retailer advertising (Figure 2). Because the baseline of the second-period demand is smaller, the two players charge higher prices in the first period as long as the damage on longterm sales is relatively small. Otherwise, players need to set lower first-period prices to sell as much as possible in the first period to mitigate pronounced negative long-term advertising effects in the second period, especially when consumers are very sensitive to current effects of retailer advertising.

The findings of Scenario II, in which the manufacturer does not find it optimal to support the first-period retailer advertising, are illustrated in Figure 3.

All players' decisions take higher values in the second period when advertising does not impact on the second-period demand $(\beta=0)$. The change in the players' strategies in the second period is explained by the offering of a cooperative advertising program by the manufacturer, which helps to increase retailer advertising and stimulate consumer demand. This finding is consistent with the current static games literature in bilateral monopoly, which supports the 


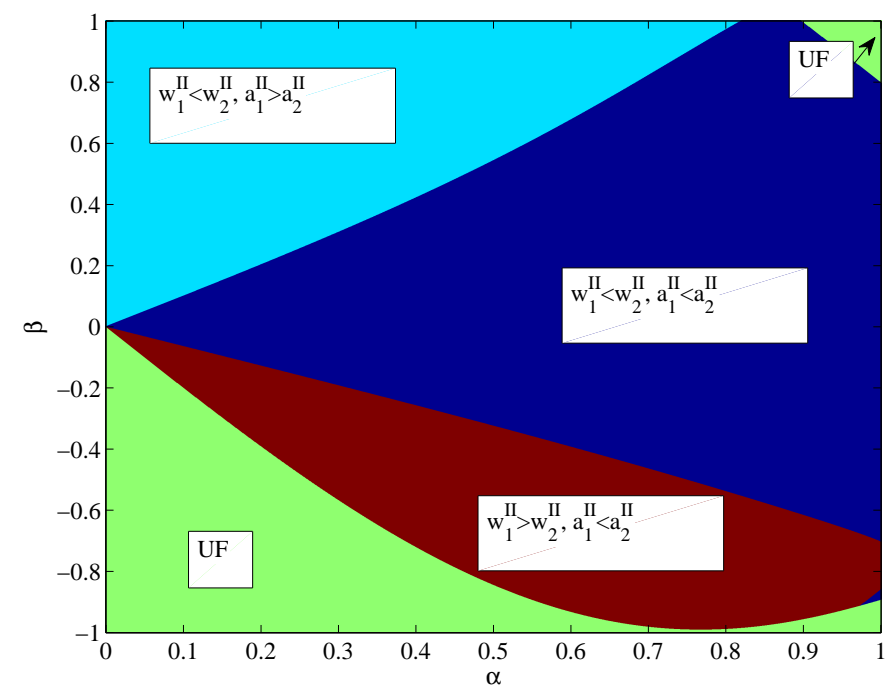

Figure 3: Scenario II: Comparison wholesale prices and advertising investments for the first and second periods.

view that cooperative advertising increases retailer advertising and consumer demand (Aust and Buscher, 2014; Jørgensen and Zaccour, 2014). Again, because the decisions and demand functions in the two periods are independent, this case corresponds to two successive static games, where the manufacturer unilaterally changes his set of decision variables from one game to another.

A dynamic game is played when the first-period advertising produces long-term effects $(\beta \neq 0)$. As expected, when retailer advertising expands the second-period demand $(\beta>0)$, the two channel members charge higher second-period prices. Surprisingly, the retailer may invest more in advertising in the first period than in the second period, especially when advertising heavily stimulates long-term sales and its effects on current sales are relatively small. Although the manufacturer does not offer any cooperative advertising support in the first period in this scenario, the relative effectiveness of advertising over time can still motivate the retailer to invest more in advertising in the first period than in the second period where 
cooperative advertising is provided.

On the other hand, when retailer advertising negatively impacts on long-term sales $(\beta<0)$, all second-period decisions are still higher than the first-period decisions, except in this case that the manufacturer may reduce his second-period wholesale price, especially when the negative long-term effect and the current effect of retailer advertising are high. The reduction of the second-period wholesale price can be considered as an additional incentive, on top of the cooperative advertising support, given to the retailer to support additional marketing activities in the second period. Such an extra incentive limits the damaging effect of the first-period advertising as the retailer is given larger margins to be used at her own discretion.

The findings of Scenario III, in which the retailer does not undertake advertising in the first period, reveal that regardless of the values of the parameters, the second-period decisions for the two players take larger values. The demand functions in the two periods are independent as the retailer does not advertise in the first period. This scenario corresponds to two successive static games, where the retailer unilaterally changes her set of decision variables from one game to another. The second-period retailer's advertising combined with the cooperative advertising support provided by the manufacturer help to expand consumer demand during this period. As a result, both the manufacturer and retailer respectively increase their wholesale and retail prices.

\section{Selecting an equilibrium}

The goal of this section is to endogenously evaluate, from each player's perspective, which of these three equilibria provide the best profits. The comparisons of the manufacturer's and retailer's optimal profits for the three different equilibria are presented in Figure 4. Analytical expressions are huge and cannot be presented here (these expressions are presented in Appendix A). The region where the manufacturer and retailer obtain the greatest profits when equilibrium $i$ is applied $(i=I, I I, I I I)$ are respectively denoted by $M^{i}$ and $R^{i}$ in Figure 4 .

Focusing only on $M^{i}$, Figure 4 shows that, depending on the area in the parameter space, the manufacturer can select either one of the three scenarios. For instance, the manufacturer

prefers Scenario III because it is either the only feasible scenario in certain areas or it secures the best profits when, at least, another scenario is feasible. In the latter case, Scenario III is the manufacturer's best choice when retailer advertising either harms long-term sales and is not very effective in stimulating short-term sales, or is not very effective in boosting both short-term and long-term sales.

To understand the manufacturer's preference, consider for example, the case where retailer 
advertising does not affect long-term sales $(\beta=0)$, as can be seen in Appendix $\mathrm{D}$, the two players' second-period decisions are identical in the three scenarios. The difference among these scenarios stems from the decisions of the first period and the resulting demands. The retailer advertises in the first period in Scenarios I and II and these investments can lead to higher or lower first-period demands in these two scenarios compared to Scenario III. Particularly, the manufacturer makes more profits in Scenario III than in Scenarios I and II, when the addition of retailer advertising to the mere pricing game played in the first-period of Scenario III reduces consumer demand. This happens in situations where the short-term effects of retailer advertising are not large enough to compensate its induced price increases. Otherwise, when the short-term effects of retailer advertising are very large, the manufacturer prefers Scenario I, which generates the highest demand.

Scenario III becomes even more interesting than the other two, when the first-period advertising harms long-term sales $(\beta<0)$. Because the retailer does not invest in advertising in the first period in Scenario III, the baseline demand in the second period is not negatively affected and this gives the possibility to all channel members to charge higher prices and earn more profits in the second period. The opposite applies to the situation where the first-period advertising expands the second-period baseline demand $(\beta>0)$ as Scenarios I and II become more attractive in the second period. The difference between these two scenarios is explained by the manufacturer's first-period cooperative advertising in Scenario I and its impact on both pricing and advertising decisions in the two periods.

Considering exclusively $R^{i}$ in Figure 4, it is easy to see that the retailer prefers Scenario III, either at the bottom of the figure when advertising significantly damages the second-period sales or the adoption of a continuous advertising schedule becomes extremely expensive due to large short-term and long-term effects (top right of Figure 4). Observe that in these two areas, Scenario I is not feasible. Between these two extreme regions, where the three scenarios are feasible, the retailer prefers Scenario I in which she advertises and benefits from the manufacturer's support in each period. Thus, unless the retailer finds it optimal not to advertise in the first period (Scenario III), she is better off when the manufacturer shares her advertising expenses than when he does not. This is because the first-period cooperative advertising program stimulates retailer advertising and may boost both the first- and second-

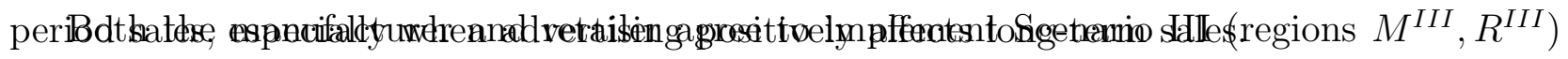

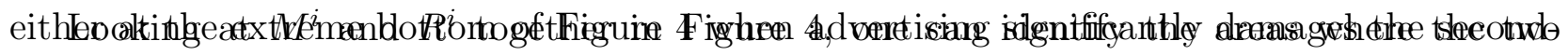

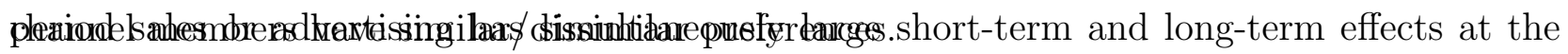
top right of Figure 4. The two channel members may also agree to implement Scenario I 


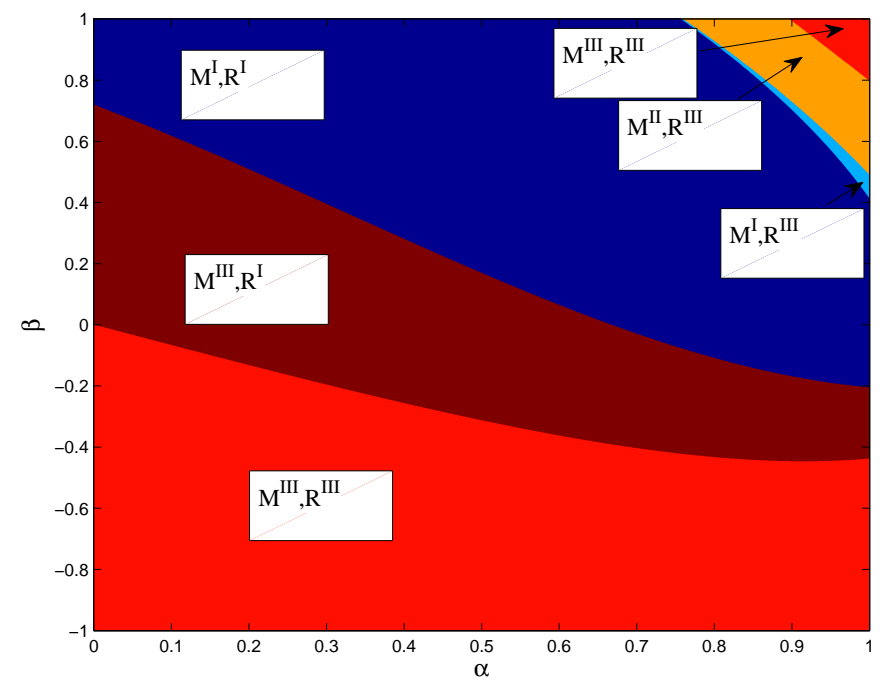

Figure 4: Channel partners' agreement regions.

(region $M^{I}, R^{I}$ ), mostly in areas where the long-term effects of advertising are positive. There are three areas of disagreement: the manufacturer and retailer respectively prefer Scenario III and Scenario I $\left(M^{I I I}, R^{I}\right)$, the manufacturer and retailer respectively prefer Scenario II and Scenario III $\left(M^{I I}, R^{I I I}\right)$, and the manufacturer and retailer respectively prefer Scenario I and Scenario III $\left(M^{I}, R^{I I I}\right)$. These situations may create conflicts within a channel unless specific actions are taken to align the interests of the parties. As the channel leader, the manufacturer may also specify up front which type of advertising qualifies for his cooperative advertising program or supply recommended layouts and copies, forcing the retailer to invest in the type of local advertising that best meets the interests of the two parties. For instance, Toyota prohibits dealer advertising that features vehicle prices below invoice that generally has a strong short-term effect, but harms sales in the long run. Mitsubishi Motors offers to its dealers an online advertising planner, which allows them to create their own ads without having to hire an advertising agency and to use pre-prepared layouts and creative copies 
(Jackson, 2004).

\section{Conclusion and discussion}

This paper analyzes how the manufacturer and retailer, in a bilateral monopoly, should respectively set their cooperative advertising support rates and levels of investment in local advertising over a two-period planning horizon. Three advertising arrangements are endogenously identified: The manufacturer offers cooperative advertising support and the retailer advertises in each period (Scenario I); the retailer undertakes advertising in the first and second periods, while the manufacturer only supports the second-period advertising (Scenario II); and the retailer only advertises in the second period and receives support from the manufacturer (Scenario III). The decision to implement either one of the three scenarios critically depends on the short-term and long-term effects of retailer advertising. The two channel members can agree to play either Scenario I or III. The analysis of the players' strategies over time for each of the three scenarios reveals that the long-term effects of retailer advertising influence how the players set their decisions from one period to another in Scenarios I and II. Conversely, the long-term effects of advertising do not affect the players' strategies in Scenario III as the retailer does not advertise in the first period.

The findings of this research extend the existing literature and offer a integrative framework that better explains observed practices in the business world and complement the findings of previous static and differential games-based models. Static game models overlook the long-term effects of advertising. Our findings suggest that the long-term effects of retailer advertising should not be ignored, as they affect the players' strategies and their changes over time. On the other hand, differential games-based models mainly prescribe continuous retailer advertising and constant cooperative advertising support rates over time (e.g., Jørgensen et al., 2003; He et al. 2011; Sigué and Chintagunta, 2009; Zhang et al., 2013). We found that constant cooperative advertising rates over time are not optimal when the first-period advertising impacts on the second-period demand (Scenario I).

Another distinctive contribution of this research is that players can endogenously change their decisions to invest or not to invest in advertising over time to maximize their respective profits over the two periods. Channel members should therefore examine alternate advertising schedules such as pulsing, as described in the advertising literature (Dubé et al., 2005; Mahajan and Muller, 1986; Mesak and Ellis, 2009; Sasieni, 1989; Villas-Boas, 1993). As a matter of fact, the existence of the two corner equilibria shows that, the manufacturer can postpone his cooperative advertising program to a later start, while the retailer pursues a continuous 
advertising strategy from the beginning (Scenario II). Also, the retailer can find it optimal to delay advertising for the second period regardless of whether or not the manufacturer offers to support first-period advertising (Scenario III). While there are many reasons for which retailers may not participate in cooperative advertising programs (a few examples are: lack of money to afford one's share of expenses, lack of information, and exogenous factors associated with a cooperative advertising program), this research claims that the eligibility requirements that define the type of advertising supported by manufacturers such as Honda, Mitsubishi, and Toyota in the automobile industry should not be overlooked. Both the short-term and long-term effects of advertising are critical in determining whether or not retailers should prefer Scenario III.

The findings of this research also have practical relevance and can help managers to better design their pricing and advertising decisions over time. The conventional wisdom in the channel literature is that retailer advertising mainly stimulates short-term sales. Previous differential games-based models have acknowledged that retailer advertising may have various long-term effects (Jørgensen et al., 2000, 2003). Empirical research in the automobile industry also supports the existence of retailer advertising carryover effects (Herrington and Dempsey, 2005). We apply this knowledge base to a two-period game setup, which can easily be visualized in a business context and help to deal more effectively with time-limited cooperative advertising contracts. Our findings support the view that when cooperative advertising programs are offered one after the other as observed in many industries, their optimal support rates can change from one period to another depending on the type of retailer advertising that the manufacturer wants to stimulate (Kachadourian, 2005). In addition, manufacturers can design their cooperative advertising programs to find the right balance between stimulating short-term sales and maintaining the value of their brands. Similarly, manufacturer can gradually decrease their support to brand-enhancing advertising activities for new products as they move towards maturity.

We have simplified our model specification to derive meaningful analytical results. Some of our assumptions can be relaxed to deal with more complex situations. For instance, the manufacturer may be given the possibility of also undertaking national advertising to complement the retailer's advertising efforts. Consumer sensitivity to price and advertising may change from one period to another as it is often the case for seasonal products (MartínHerrán et al., 2010). An expansion to a three-period game could be considered to investigate the long-term effects of the second-period retailer advertising and how they impact on both the players' strategies and profits. Competition could be added to take into account pricing 
and advertising horizontal interactions between manufacturers and/or retailers.

\section{References:}

[1] Aust, G., \& Buscher, U. (2014). Cooperative advertising models in supply chain management: A review. European Journal of Operational Research, 234, 1-14.

[2] Berger, P. D. (1972). Vertical cooperative advertising ventures. Journal of Marketing Research, 9, 309-312.

[3] Chintagunta, P., \& Jain, D. C. (1992). A dynamic model of channel member strategies for marketing expenditures. Marketing Science, 11(2), 168-188.

[4] Chu, W., \& Desai, P. S. (1995). Channel coordination mechanisms for customer satisfaction. Marketing Science, 14, 343-359.

[5] Cole, A. (2015). Toyota asking dealers to stop advertising below invoice, world not over yet. The Truth About Care:http://www.thetruthaboutcars.com/2015/08/toyota-askingdealers-stop-advertising-invoice-world-not-yet/ Accessed on June 10, 2016.

[6] Dubé, J-. P., Hitsch, G. J., \& Manchanda, P. (2005). An empirical model of advertising dynamics. Quantitative Marketing and Economics, 3, 107-144.

[7] He, X., Krishnamoorthy, A., Prasad, A., \& Sethi, S.P. (2011). Co-0p advertising in dynamic retail oligopolies. Decision Sciences, 42(4), 923-944.

[8] Herrington, J. D., \& Dempsey, W. A. (2005). Comparing the current effects and carryover of national-, regional-, and local-sponsor advertising. Journal of Advertising Research, March, 60-72.

[9] Honda Canada Inc. (2010). Co-op advertising. http://motorcycle.honda.ca/Content/mcpead-

builder.ca/3660c2dd-cfb9-45d4-bd0b-a489d15e2697/AdBuilderAsset/Honda_Co_Op_Policy _EN_v2.pdf). Accessed on July 16, 2016.

[10] Huang, Z., \& Li, S. X. (2001). Co-op advertising models of manufacturer-retailer supply chains: A game theoretic approach. European Journal of Operational Research, 135, 527544.

[11] Jackson, K. (2004). Mitsubishi shakes things up. Automotive News, April 5. 
[12] Jørgensen, S., Sigué, S. P., \& Zaccour, G. (2000). Dynamic cooperative advertising in a marketing channel. Journal of Retailing, 76, 71-92.

[13] Jørgensen, S., Sigué, S. P., \& Zaccour, G. (2001). Stackelberg leadership in a marketing channel. International Game Theory Review, 3(1), 1-14.

[14] Jørgensen, S., Taboubi, S., \& Zaccour, G. (2003). Retail promotions with negative brand image effects: Is cooperation possible? European Journal of Operational Research, 150, 395-405.

[15] Jørgensen, S., \& Zaccour, G. (2014). A survey of game-theoretic models of cooperative advertising. European Journal of Operational Research, 237, 1-14.

[16] Kachadourian, G. (2005). Wild dealer promotions pull in potential buyers. Automotive News, 79(6132), 34-36.

[17] Karray, S. (2013). Periodicity of pricing and marketing efforts in a distribution channel. European Journal of Operational Research, 228, 635-647.

[18] Karray, S. (2015). Cooperative promotions in the distribution channel. Omega, 51, 49-58.

[19] Karray, S., \& Amin, S.H. (2015). Cooperative advertising in a supply chain with retail competition. International Journal of Production Research, 53 (1), 2015.

[20] Karray, S., \& Zaccour, G. (2006). Could co-op advertising be a manufacturer's counterstrategy to store brands? Journal of Business Research, 59, 1008-1015.

[21] Li, S., Huang, Z., Zhu, J., \& Chau, P. (2002). Cooperative advertising game theory and manufacturer-retailer supply chains. Omega, 30(5), 347-357.

[22] Lilien, G. L., Kotler, P., \& Moorthy, K. S. (1992). Marketing Models. New Jersey: Prentice Hall.

[23] Mahajan, V., \& Muller, E. (1986). Advertising pulsing policies for generating awareness for new products. Marketing Science, 5(2), 89-106.

[24] Martín-Herrán, G., \& Sigué, S. P. (2011). Prices, promotions, and channel profitability: Was the conventional wisdom mistaken? European Journal of Operational Research, $211(2), 415-425$. 
[25] Martín-Herrán, G., Sigué, S. P., \& Zaccour, G. (2010). The dilemma of pull and pushprice promotions. Journal of Retailing, 86(1), 51-68.

[26] Mesak, H. I., \& Ellis, T. S. (2009). On the superiority of pulsing under a concave advertising market potential function. European Journal of Operational Research, 194, 608-627.

[27] Mitsubishi Motors. (2012). Individual co-op assitance program: $\quad$ http://tempe.acbcoop.com/paranet60/clientdocs/mitsubishinamultipoint/2012coopguidelines04-06.pdf/ Accessed on July 21, 2016.

[28] Sasieni. M. W. (1989). Optimal advertising strategies. Marketing Science, 8(4), 358-370.

[29] Sigué, S. P. (2008). Consumer and retailer promotions: Who is better off? Journal of Retailing, 84(4), 449-460.

[30] Sigué, S. P., \& Chintagunta, P. (2009). Advertising strategies in a franchise system. European Journal of Operational Research, 198 (2), 655-665.

[31] Szmerekovsky, J.G., \& Zhang, J. (2009). Pricing and two-tier advertising with one manufacturer and one retailer. European Journal of Operational Research, 192, 904-917.

[32] Villas-Boas, J. M. (1993). Predicting advertising pulsing policies in an oligopoly: A model and empirical test. Marketing Science, 12(1), 88-102.

[33] Wolfram Research, Inc. (2010). Mathematica Edition: Version 10.0. Wolfram Research, Inc. Champaign, Illinois.

[34] Xie, J., \& Ai, S. (2006). A note on "cooperative advertising, game theory and manufacturer-retailer syupply chains". Omega, 34, 501-504.

[35] Yan, R. (2010). Cooperative advertising, pricing and firm performance in the e-marketing age. Journal of the Academy of Marketing Science, 38, 510-519.

[36] Yan, R., Cao, Z., \& Pei, Z. (2016). Manufacturer's cooperative advertising, demand uncertainty, and information sharing. Journal of Business Research, 69, 709-717.

[37] Yan, R., \& Pei, Z. (2015). The strategic value of cooperative advertising in the dualchannel competition. International Journal of Electronic Commerce, 19(3), 118-143.

[38] Zhang, J., Gou, Q., Liang, L., \& Huang, Z. (2013). Supply chain coordination through cooperative advertising with reference price effect. Omega, 41, 345-353. 
[39] Zhang, J., Cou, Q., Li, S., \& Huang, Z. (2015). Cooperative advertising with accrual rate in a dynamic supply chain. Dynamic Games and Applications. Published online 04 August 2015. DOI: 10.1007/s13235-015-0165-z 